\title{
LVIII. On the edge-angle and spread of liquids on solid bodies
}

\section{G. Quincke}

To cite this article: G. Quincke (1878) LVIII. On the edge-angle and spread of liquids on solid bodies, Philosophical Magazine Series 5, 5:33, 415-433, DOI: 10.1080/14786447808639451

To link to this article: http://dx.doi.org/10.1080/14786447808639451

Published online: 13 May 2009.

Submit your article to this journal $\pi$

Џ Article views: 3

Q View related articles $\sqsubset$ 
only with the direction of the current, but likewise with its strength, and to some extent also with its duration. To construct a selenium resistance for exact measuring-purposes, coefficients for all these changes would have to be determined, at very considerable trouble; and when determined, the inconstancy of the material is such that they would probably soon be altogether inapplicable.

In preparing the apparatus and making the experiments, I have been greatly indebted to the efficient aid rendered me by Mr. MeEniry.

Grosmont House, Hampton Wick, May 1, 1.878 .

LVIII. On the Edge-angle and Spread of Liquids on Solid Bodies. By G. QUINCKE.

[Concluded from p. 339.]

10. SPREAD of Liquids upon the Surface of Solid Bodies. -It is possible to form an opinion in another manner than by direct measurements, about the magnitude of the surface-tension at the boundary of a fluid and of a solid body, from the magnitude of the edge-angle which a fluid-surface forms with a solid body.

From equation ( 5 ) follows at once

$$
\alpha_{21}>\alpha_{13}
$$

if the edge-angle $\theta$ of the common bounding-surface of the fluids 2 and 3 with the solid body 1 is an acute angle for fluid 3.

For glass as the solid body, and water as fluid 3, and for bisulphide of carbon, chloroform, olive-oil, turpentine, petroleum, or mercury as fluid 2, this condition is fulfilled with the slight allowances already explained* for impurity of the solid surface of glass.

The water will therefore have a greater adhesion to glass than the fluids named.

Whenever free fluid-surfaces bounded by air are absent, none of the fluids 2 investigated drives the water away from the glass surface, however different in magnitude may be their capillary constants. 'i'he edge angle was only in rare cases $0^{\circ}$; consequently the water also usually did not drive the other fluids from the glass surface.

* Compare the researches upon flat drops and bubbles, Pogg. Ann. cxxxix. pp. 18-20, 22 (1870); upon submerged capillary tubes, ibitl. pp. 42-44; upon the ascent in capillary tubes of several superposed fluids, ibid. pp. 50-52. And in Phil. Mag. April, May, and June, 1871. 
That the phenomena produced by the same liquids may change with the nature of the solid substance follows from the researches of Chevreul ${ }^{*}$, in which, when air was excluded, olive-oil was driven away by water in porous porcelain, while in porous whitelead water was driven away by olive-oil.

This circumstance is therefore worthy of notice, since it has often been said that fluids with a lesser capillary constant, or tension of the free surface, drove away from solid bodies the fluids with a greater capillary constant of the free surface. If the fluids are brought into contact with the air, besides being brought into contact with one another and with the solid substance, then indeed the water is driven away by most of the fluids 2 with which the researches recited above were conducted; and I have already previously completely discussed the cause of this phenomenon. Hence it follows that the contact of air with fluids 2 and 3 , which are in contact with a solid body 1 , may promote or initiate the driving away of fluid 3 by fluid 2 from the surface of a solid body, when once $\alpha_{2}<\alpha_{3}$, and in consequence the sum of the surfacetensions a minimum $\neq$.

This remark appears to me to be of importance for the comprehension of the influence of the air, or of gases generally, upon the processes of diffusion in the nourishment of plants and animals, and in the influence upon the digestion of drinks containing carbonic acid.

If two fluids, which are mutually miscible in all proportions, come into contact with the same solid body (with glass in the present case) simultaneously, without access of air, there can be no surface-tension at the surface of contact of the two fluids, and the fluid of the lesser surface-tension $\alpha_{12}$ of the common boundary with the glass must drive away from the solid body the fluid with the greater surface-tension.

According to the figures of Tables VIII. and IX., water must therefore drive away alcohol from a surface of glass. This is in harmony with experience, since burnt clay and quartz-sand, which behave sinilarly to glass, deprive aqueous alcohol of water, as Wagenmann and I have found $\S$.

According to Table IX. turpentine must drive olive-oil

* Comptes Rendus, 1xiii. p. 63 (1866).

$\dagger$ Pogg. Ann. cxxxix. p. $5 \delta$ (1870); and Phil. Mag. Jume 1871, pp. 466-9.

$\ddagger$ Pogg. Ann. cxxxix. p. 61 (1870); and Phil. Mag. June 1871, p. 471.

\$ Pogg. Ann. cx. p. 61 (1860). Compare also W. Schmidt, Pogg. Ann. xcix. p. 370 (1856), and Duclaux, Ann. de Chim. et Phys. (4) xxv p. $486(1875)$. 
away from a glass surface; the contrary must occur according to Table VIII.

In fact the first occurs, since, as I formerly* proved by the change of height of capillary ascent, in a capillary tube filled with olive-oil and dipped in turpentine, the latter drives away the olive-oil, and finally spreads upon the surface of the olive-oil.

In the case of all aqueous saline solutions which are miscible with water in all proportions, the saline solution must drive away the water from the surface of the glass the more easily the more concentrated it is, since $(\alpha)$ increases $\dagger$ with augmented concentration, and, as is shown in detail in $\$ 9$, $\alpha_{12}$ is the smaller as $(\alpha)=\alpha_{2} \cos \theta$ is greater for the free surface of the liquid.

The same must also occur in the case of different saline solutions which are miscible in all proportions, and which exercise no chemical action upon one another (as giving precipitates \&c.).

Since for all saline solutions the edge-angle against glass has nearly identical values, the saline solution with the greater cohesion $(\alpha)$ will drive away from the surface of the glass that with lesser cohesion.

Hence it follows, further, that from a dilute saline solution, as a mixture of water of less cohesion with concentrated saline solution of a greater, there must collect on the surface of the glass a concentrated solution. The most soluble substances, which in strong concentration exhibit the greatest cohesion, must also collect specially readily on the surface of glass, or will be specially strongly absorbed by the glass surface.

The phenomena of so-called selective absorption appear to confirm this. Quartz, porcelain, \&c., which have for saline solutions an edge-angle similar to that of glass (compare $\$ 7$ above), appear to absorb carbonate of potash, chloride of calcium, chloride of magnesium, \&c. specially strongly, and hence, therefore, those salts which with strong concentration exhibit the greatest cohesion $(\alpha)$.

This is in harmony with experience in the fact that new, unused porcelain cylinders (such as are usually employed in galvanic batteries), when they have once been in contact with a dilute saline solution, retain salt absorbed even after a longprotracted steeping in water.

The influence of the molecular nature of the solid substance exhibits itself specially clearly in the case of lightly and

* Pogg. Ann. cxxxix. p. 55 (1870).

$\uparrow$ Ibid. clx. p. 371 (1877).

Phil. Mag. S. 5. Vol. 5. No. 33. June. 1878. 
strongly ignited carbon; the former exhibits, according to the researches of Graham*, a very strong selective absorption, the latter an absorption scarcely perceptible.

On account of the difficult mobility of saline solutions on the surface of glass, and the residual attraction of water to a concentrated saline solution (here disregarded), the concentrated saline solution may certainly become partially dissolved away and removed from the surface of the glass; and this solution leads directly to a theory of diffusion at the surface of solid bodies.

11. Brücke $\dagger$ has founded his theory of the diffusion of a liquid at the surface of solids upon researches with turpentine and cotton-seed oil, which were brought into contact with one another in a space bounded by nearly-adjacent surfaces of glass.

According to Briicke the turpentine drives the cotton-seed oil from the glass surface. The liquid filling the capillary space may be divided into three films, of which the middle one consists of turpentine and cotton-seed oil, and the surface layers of turpentine. Whilst from the turpentine side of the middle layer cotton-seed oil is continually withdrawn, and turpentine continually from the cotton-seed-oil side, since the turpentine of the surface-film is attracted more strongly by the cotton-seed oil than by the turpentine in the vessel, some of this continually wanders over into the cotton-seed oil, and the volume of the latter is augmented.

This theory of the diffusion of turpentine and cotton-seed oil upon a glass surface is deduced from the supposition that the turpentine drives away the cotton-seed oil from the surface of glass. Brücke founds this supposition upon the experiment that a small drop of cotton-seed oil placed upon a clean glass plate is driven away by a neighbouring drop of turpentine. The attraction of glass to turpentine is too great, relatively to that of turpentine to itself, for the contact-angle between these two substances to approach $180^{\circ}$.

But where the turpentine meets the cotton-seed oil it drives it away from itself by virtue of its greater adhesion.

So, consequently, the experiment just described does not prove this supposition, since in it the liquids, besides being in contact with one another and with glass, are also in contact with air. Nevertheless the supposition laid down as the foundation of the theory is right, as my researches mentioned above $(\$ 10)$ show, where, without access of air, the

* Pogg. Anu. xix. p. 139 (1830).

$\uparrow$ Tbid. lriii. p. 82 (1843). 
turpentine drove the cotton-seed oil from the surface of glass. Brücke's theory of the diffusion of liquids at the surface of solid bodies satisfies every postulate when once the spread of one of the liquids upon the surface of the solid has been explained.

As already mentioned above, a liquid 2 with a small capillary tension $\alpha_{12}$ at the boundary of a solid body 1 , must drive away a liquid 3 possessing a greater capillary tension $\alpha_{13}$ at the boundary of the same solid body, provided access of the air is prevented and that the liquids 2 and 3 are miscible in all proportions. In this case $\alpha_{2}=0$, and equation $(6 \mathrm{~A})$ is immediately fulfilled.

Liquids which are miscible in all proportions may also be arranged in relation to any given solid body 1 in a determinate series according to the magnitude of the capillary constant or surface-tension of the common boundary of the solid body and of the liquid in question. Each liquid will be driven away by one standing lower in this series. But the series changes with the nature of the solid body.

I have detailed above $(\$ 9$, conclusion) the difficulties which beset an exact determination of the magnitudes $\alpha_{12}, \alpha_{13}$, \&c.

In view of the uncertainty of inferring the surface-tension of the boundary of liquids and solids from observations on flat drops, the method of observing directly the spread of a liquid on the surface of a solid body when air is excluded deserves at least the preference.

The method employed by me in the case of olive-oil and turpentine cannot unfortunately be applied to all liquids, and fails where no diminution of the capillary height of ascent can be observed, and when the liquid with the greater capillary constant of the free surface is such that it spreads upon the surface of the solid. This is, for example, the case with water and alcohol upon the surface of glass.

The influence upon the diffusing liquids of the dependence of diffusion upon the nature of the solid body is beautifully shown in the case of alcohol and water which are separated by a piece of pig's bladder or by india-rubber tissue. In the first case the volume of the water diminishes ; in the second it increases.

Here Brücke* has already shown, by experiment, that on the exclusion of air the water overspreads the surface of the bladder, and the alcohol invests the surface of the indiarubber tissue- that therefore in the first case the water can flow to the alcohol, in the second the alcohol can flow to the water.

* Pogg. Ann. lviii. p. 87 (1843). 
Such a porous partition behaves similarly to a more or less completely closed valve, and permits, according to its nature or chemical properties, the liquid 2 to flow towards liquid 3 , or liquid 3 towards liquid 2 .

The experiments mentioned show that

$$
\begin{aligned}
& \alpha \text { (water, bladder) }<\alpha \text { (alcohol, bladder) } \\
& \alpha \text { (water, indiarubber) }>\alpha \text { (alcohol, indiarubber). }
\end{aligned}
$$

The surface-tension at the boundary of a liquid and a solid body appears, like the surface-tension at the boundary of two liquids, to be less in proportion as one liquid is the more able to dissolve the other body.

Besides, it is in most cases very difficult, in single experiments, to distinguish the surface-diffusion through the interposition of the solid partition from the free diffusion which occurs between two liquids without the interposition of the solid partition. That is also the reason why these processes have hitherto been so little investigated.

Since the friction of the liquid particles against one another decreases with augmenting temperature, with an augmenting temperature the diffusion must increase for equal differences between the magnitudes $\alpha_{12}$ and $\alpha_{13}$, where again the solid is denoted by 1 and the diffusing liquids by 2 and 3 . And experience generally* agrees therewith.

12. Imperceptibly thin flus of liquid. Creeping of salts.Many times already have I drawn attention to the want of harmony between theory and the observed facts, and at the conclusion of $\$ 9$ have inferred therefrom that imperceptibly thin films of a foreign substance upon the surface of the solid body may be the cause of this accidental circumstance.

On account of the numerous observations, and the accuracy of the methods employed, it is specially remarkable that in the measurements upon air-bubbles in aqueous saline solutions an edge-angle of from $20^{\circ}$ to $30^{\circ}$ is generally found, and yet by the direct method of reflexion a much smaller value is found.

It implies this, according to my thinking :- that clean liquids spread instantly upon the clean surface of solid bodies, just as clean fluids spread instantly upon the clean surface of mercury ; and that if no spread occur, and the edge-angle differ from $0^{\circ}$, the surface of the solid body, like that of the mercury, is always coated with an excessively thin film of a foreign substance which hinders the spread.

This thin film (which itself escapes observation, because it

* Brücke, Pogg. Ann. lviii. p. 78 (1843). 
is so thin that it can only be perceived in solitary cases with difficulty and by optical aids) may itself consist of the liquid whose drops have been placed upon the surface of the solid body.

As a drop of oil, placed upon a clean surface of water, divides itself when sufficiently large into two parts, of which one part is drawn in a very thin film over the clean watersurface, whose capillary constant or surface-tension is diminished, thereby rendering it possible that the rest of the oil may remain lying in a lenticular globule * upon the modified surface of the water, so when water or aqueous saline solutions are placed upon the clean surface of a solid body, a portion of the liquid spreads out in an excessively thin film upon the solid surface. The original surface-tension (if we retain the expression on account of the analogy with clean surfaces of liquid) of the clean solid surface is thereby diminished; the remainder of the liquid stays upon the modified solid surface in a lenticular form, and with an edge-angle $>0^{\circ}$.

This film of foreign liquid forming over the surface of the solid body at the first moment with very great rupidity, is of a thickness varying with the temperature and purity of the surface, and is usually thinner than the double radius $2 l$ of the sphere of sensible action, or greater than 0.000050 millim. But according to the rapidity of the spread or of the formation this film has different thicknesses and different properties, and modifies the tension of the previously clean surface of the solid substance in different manners also. The change of density which the liquid in the immediate neighbourhood of the solid surface experiences must depend upon the time during which the molecular forces of adhesion act upon these liquid particles.

Upon a liquid particle at a distance $<l$ from the solid wall there acts the difference of the molecular forces which are exerted by the substance of the solid wall in one direction, and by the substance of the liquid and air lying on the other side of it in the opposite direction.

The action of the air is negligibly small; and one may therefore say that upon the liquid particles in the immediate neighbourhood of the solid wall there is exerted a greater molecular force, and that the change of density thereby produced is greater, in proportion as the film of liquid which lies over it is thinner. The change of density will be different at different distances from the solid wall, and at given points

* Pogg. Ann. cxxxix. p. 76 (1870). 
of the liquid will be the greater as the whole film of liquid which covers the solid body is thinner.

But since the change of density is propagated from particle to particle, it may very well be observable, even at a distance, $>l$, or greater than $p l$, where $p$ may signify a factor greater than 2.

These changes of the density and molecular properties of the liquid, which in the so-called imperceptibly thick films that overspread the surfaces of solid bodies, play a considerable part in all phenomena concerning the attraction of fluids to other fluids or solid bodies, and make the investigation of these phenomena the more difficult, since we know very little or nothing of the magnitude and nature of the changes, and consequently cannot bring them into our calculations.

The phenomenon not theoretically explicable, that a drop of oil upon a water-surface covered with a thin oil-film, or a drop of water upon a glass-surface covered with a thin waterfilm remains in a lenticular form, depends probably upon some such modification of the liquid in the thin liquid film.

Whether the difficult mobility of a lenticular drop of liquid on a level solid surface (compare $\$ 4$ ) is also determined by the presence of an imperceptibly thin film of liquid, as I formerly* observed in the case of liquid surfaces, or whether the difficult mobility of the solid substratum is also involved, cannot be decided with certainty off-hand. The fact that upon the cleanest possible solid surfaces the liquids can spread with remarkable rapidity points to the former suggestion.

These thin films of liquid, modified by the proximity of a heterogeneous substance, play a great part in nature; and there is certainly no doubt that the life of organic nature depends principally upon them.

That these films, whose thickness in many cases amounts only to a small fraction of the mean length of a wave of light, cannot be seen, is a physical difficulty for investigation, but no proof against their existence. In the investigation of the common surface of different liquids I have already remarked $\dagger$ upon this circumstance, and hinted at the difficulties involved in the investigation.

But it is possible to prove the existence of these thin films in another way than by the edge-angle at the boundary of a drop of liquid on a level solid body. Newton's rings were

* Pogg. Ann. cxxxix. p. 7I (1870). Compare also Marangoni, Cimento, v. p. 239 (1872) ; Berol. Ber. xxviii. p. 184 (1872).

† Pogg. Ann. cxxxix. pp. 37,39,69, 73-76 (1870); and Phil. Mag. [IV.] vol. xli. (1871). 
exhibited by aqueous solutions of carbonates of soda and potash on the glass plate under which the bubbles of air lay*.

But even in those cases where the film is so thin that interference-colours fail, there are formed, on the surface of the solid substance, near the sharply-defined flat drop of a saline solution, crystals of the salt employed, or, as the phenomenon has been well named, the salt creeps.

The creeping, or efflorescence, of the salts is usually explained $\dagger$ by the liquid which is drawn up between the wall of the vessel and the salt which has crystallized out. This explanation is legitimate when once the first crystals have formed. The formation of these first crystals, however, which often form upon the solid surface at a great distance from the liquid, is determined by the thin film of saline solution which overspreads all solid bodies (metals, glass, quartz, \&c.) in imperceptible thickness. If a portion of the water evaporates, a fresh quantity of the saline solution streams into the interior of the thin film. The thickness of the film and the proportion of the inflowing saline solution are the greater as the surface of the solid body is the cleaner.

Temperature also appears to have an essential influence upon the rapidity of the liquid mixture flowing into the thin film.

The crystals of the salt form where the water evaporates most rapidly, at the outermost edge of the thin liquid film.

Frequently the surface of the solid body is unequally clean at different points; and then the crystals form first on the cleanest places, and at a greater distance from the flat drops of liquid than on the places that are less clean.

The creeping is the more striking as the solid surface is cleaner, or as the edge-angle at the boundary of the flat liquid drop is less (since this latter depends closely, as I have shown above, upon the former).

Creeping does not oceur if the solid surface be covered with a thin film of oil. Since glass surfaces remain clean longer in the open air than metal surfaces, salts usually creep more readily upon the former than upon metal surfaces. Besides, it has long been known that the creeping of salts may be hindered by smearing a glass surface with grease.

Moreover those salts whose solutions in the requisite concentration are most mobile must exhibit creeping the most

* Pogg. Ann. clx. p. 369 (1877).

† Compare Barentin, Handwörterbuch der Chemie und Physik, p. 636 (1842). 
plainly: hence liquids having minimum viscosity or maximum fluidity, must exhibit, cceteris paribus, the most considerable creeping. With this the facts appear, in general, to harmonize; for solutions of salammoniac, saltpetre, and potassium chloride, liquids possessing great fluidity*, exhibit the phenomenon of creeping to a special degree.

13. Demonstration of thin Liquid-films by Electric Discharges. - In addition to the methods of the edge-angle and of the phenomena of creeping, the existence of the thin liquidfilm near the flat drops of liquid upon a solid surface may be proved by a third electrical method, provided the solid substance be an insulator (e.g. glass), and the liquid upon it be a conductor of electricity.

Two vertical platinum wires, $\mathrm{P}_{1}$ and $\mathrm{P}_{2}$ (Plate XII. fig. $1 d$ ), of 0.138 millim. diameter, were ignited in a flame of pure alcohol, and placed at 8 millims. distance from one another upon a horizontal piece of plate glass of 60 millims. length and 40 millims. breadth, which again lay upon a larger horizontal piece of plate glass. At a certain time the wire $P_{1}$ was connected to a charged gold-leaf electroscops by a long thin silver wire; the other wire, $\mathrm{P}_{2}$, leading to earth.

Each platinum wire was fastened with shellac to the corner of a triangle of plate-glass of 35 millims. width and 3 millims. thickness. Each formed, along with two similarly fastened plated copper wires, the leg of a little tripod 23 millims. high, whose weight pressed it lightly against the surface to be investigated.

With a seconds' watch, or a metronome beating half seconds, the time $\tau_{0}$ was estimated which was required for the gold leaves 18 millims. long and 2 millims. broad, of an electroseope to fall together from an angular separation of $60^{\circ}$. The same experiment was then again repeated and the time $\tau$ of the discharge of the electroscope measured, after a flat drop of water or saline solution had been deposited near the platinum wires without touching them. Simultaneously the edge-angle $\theta$ was measured by the method of reflexion (see $\S 3$ ).

It was found that $\tau_{0}$ and $\tau$ were greater or less according as a longer or shorter time $Z$ had elapsed since the cleansing of the plate glass. But $\tau$ was always much less than $\tau_{0}$, and in general was only half as great as $\boldsymbol{\tau}_{0}$.

As examples I subjoin a series of such determinations, where oppositè each solution is stated in brackets whether 1 , or $\frac{1}{2}$, or $\frac{1}{4}$ volume of the concentrated solution was contained in 1 volume of the liquid employed.

* O. E. Meyer, Pogg. Ann. cxiii. p. 404 (1861); and Grotrian, Pogg. Ann. clvii. p. 243 (1876). 


\section{Table X.}

\begin{tabular}{|c|c|c|c|c|}
\hline Liquid. & $\begin{array}{l}\text { Time } \\
\text { since } \\
\text { plate } \\
\text { was } \\
\text { cleansed. } \\
Z \\
Z\end{array}$ & \multicolumn{2}{|c|}{$\begin{array}{c}\text { Time of discharge } \\
\text { of the electroscope } \\
\text { before | after: } \\
\text { deposition of the } \\
\text { drop. }\end{array}$} & $\begin{array}{l}\text { Edge- } \\
\text { angle. } \\
\theta .\end{array}$ \\
\hline \multicolumn{5}{|c|}{ Black Glass. No. 1.} \\
\hline 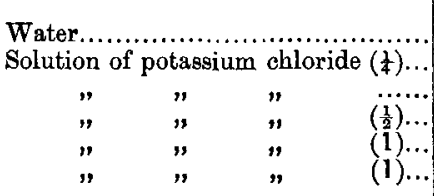 & $\begin{array}{l}0 \text { h. } \\
3 \\
24 \\
? \\
0 \\
48\end{array}$ & $\begin{array}{l}\ddot{0} \cdot 65 \\
1 \cdot 75 \\
42 \\
2 \cdot 75 \\
1 \\
9\end{array}$ & $\begin{array}{l}\ddot{0} \cdot 32 \\
0 \cdot 6 \\
22 \\
1 \\
0 \cdot 4 \\
4\end{array}$ & $\begin{array}{rr}\circ & 9 \\
4 & 57 \\
4 & 7 \\
21 & 55 \\
18 & 58 \\
4 & 32 \\
12 & 25\end{array}$ \\
\hline \multicolumn{5}{|c|}{ Black Glass. No. 2.} \\
\hline 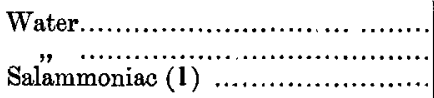 & $\begin{array}{l}0 \mathrm{~h} . \\
1.5 \mathrm{~b} . \\
8 \text { days }\end{array}$ & $\begin{array}{r}45 \\
285 \\
196\end{array}$ & $\begin{array}{r}18 \\
120 \\
115\end{array}$ & $\begin{array}{lr}12 & 58 \\
37 & 4 \\
20 & 52\end{array}$ \\
\hline \multicolumn{5}{|c|}{ Plate Glass. } \\
\hline 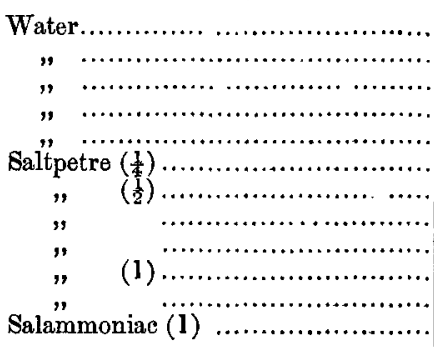 & $\begin{array}{l}0 \text { h. } \\
24 \\
48 \\
0 \\
0 \\
12 \\
0 \\
24 \\
8 \text { days } \\
0 \text { h. } \\
14 \text { days } \\
?\end{array}$ & $\begin{array}{l}6 \\
3 \cdot 5 \\
1 \cdot 55 \\
1 \cdot 65 \\
15 \\
2 \cdot 5 \\
18 \cdot 5 \\
8 \\
50 \\
14 \\
200 \\
52\end{array}$ & $\begin{array}{l}\mathbf{4} \\
2 \cdot 5 \\
0 \cdot 2 \\
1 \cdot 05 \\
\mathbf{3} \cdot 5 \\
1 \cdot 5 \\
13 \\
\mathbf{2} \cdot 5 \\
11 \\
\mathbf{2} \\
32 \\
\mathbf{2 7}\end{array}$ & $\begin{array}{rr}3 & 16 \\
5 & 0 \\
4 & 52 \\
7 & 44 \\
13 & 13 \\
13 & 13 \\
22 & 43 \\
5 & 4 \\
34 & 42 \\
5 & 22 \\
29 & 0 \\
27 & 12\end{array}$ \\
\hline \multicolumn{5}{|c|}{ Quartz. } \\
\hline 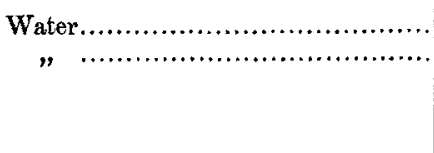 & $\begin{array}{l}0 \text { b. } \\
0\end{array}$ & $\begin{array}{l}19 \cdot 5 \\
140\end{array}$ & $\begin{array}{l}12 \cdot 5 \\
50\end{array}$ & $\begin{array}{l}3629 \\
1454 \\
\text { cleansed } \\
\text { with a } \\
\text { cloth. }\end{array}$ \\
\hline \multicolumn{5}{|c|}{ Selenite. } \\
\hline 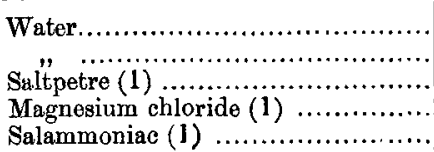 & $\begin{array}{l}0 \mathrm{~h} . \\
0 \\
0 \\
0 \\
0\end{array}$ & $\begin{array}{c}7 \cdot 5 \\
13 \\
4 \\
7 \\
8 \cdot 5\end{array}$ & $\begin{array}{l}3 \cdot 75 \\
8 \cdot 5 \\
2 \cdot 5 \\
6 \\
7\end{array}$ & $\begin{array}{rr}6 & 47 \\
2 & 25 \\
13 & 58 \\
5 & 14 \\
5 & 55\end{array}$ \\
\hline
\end{tabular}


Table (continued).

\begin{tabular}{|c|c|c|c|c|}
\hline \multirow[t]{2}{*}{ Liquid. } & $\begin{array}{c}\text { Time } \\
\text { since } \\
\text { plate } \\
\text { was } \\
\text { cleansed. } \\
\text { Z. }\end{array}$ & \multicolumn{2}{|c|}{$\begin{array}{l}\text { Time of disoharge } \\
\text { of the electroscope } \\
\text { before | after } \\
\text { deposition of the } \\
\text { drop. } \\
\tau_{0^{*}} \mid \boldsymbol{\tau} \text {. }\end{array}$} & $\begin{array}{c}\text { Edge- } \\
\text { angle. } \\
\theta .\end{array}$ \\
\hline & \multicolumn{4}{|c|}{ Mica (uniaxal). } \\
\hline Water........................ & $0 \mathrm{~h}$. & $\stackrel{11}{1} \cdot 75$ & $\ddot{0} 6$ & 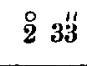 \\
\hline \multicolumn{5}{|c|}{ Mica (biaxal). } \\
\hline $\begin{array}{l}\text { Water................ } \\
\text { Saltpetre (1) ... }\end{array}$ & $\begin{array}{l}0 \mathrm{~h} . \\
0\end{array}$ & $\begin{array}{l}3 \\
2 \cdot 25\end{array}$ & $\begin{array}{l}1 \cdot 75 \\
1\end{array}$ & 215 \\
\hline
\end{tabular}

These experiments show that, other circumstances being alike, the time of discharge of the electroscope was less as the edge-angle was smaller or the surface of the solid substance cleaner.

Since the times of discharge for the same liquid were different in the different experiments, they cannot be due to the deposited drops alone, but must depend upon the state of the surface of the solid substance, which is modified in different ways by the substances deposited upon it.

The differences of time of discharge, however, are at once explained if it be admitted that a small portion of the liquid deposited spreads upon the surface of the solid substance in an extremely thin film imperceptible by optical methods, and that the remaining portion of the liquid rests with an edgeangle $>0^{\circ}$ upon the surface so modified or rendered impure by the liquid itself.

The edge-angle and the time of discharge were found to be less, according as the thin liquid film near the flat drop of liquid had a greater thickness, or as the surface of the solid substance was more completely clean.

That in the separate experiments the edge-angle and the time of discharge, or the thickness of the thin film of liquid near the flat drops, were found of different magnitudes cannot be surprising if we contemplate the difficulties which stand in the way of a complete cleansing of the plate, or if we consider how the gradually augmenting impurity of the surface is the result of accidentally settling particles of dust, the presence of which cannot be avoided, and yet whose influence cannot be allowed for. 
14. Influence of the velocity of the falling drops upon the thickness of the thin films of liquid.

The time of discharge of the electroscope appears to vary, amongst other conditions, according as the drops have formed swiftly or slowly.

On two siphons of equal diameter ( 1.006 millim.) (see $\$ 4)$ there were formed respectively 10 drops and 40 drops of water in a minute, of 19 mgrms. and $19.67 \mathrm{mgrms}$. weight each; so that in one minute about 3.28 square centims. and $14 \cdot 15$ square centims. of free surface of liquid were respectively formed per minute.

As before, the times of discharge $\tau_{0}$ and $\tau$ of the gold-leaf electroscope were determined for a distance of 8 millims. between the platinum electrodes, without and with drops of water, upon a clean glass plate. The edge-angle was also measured at the same time, according as the drops were formed slowly or rapidly.

$\mathrm{Z}$ signifies the time which had elapsed since the cleansing of the glass plate.

Table XI.

Water-Plate Glass.

\begin{tabular}{|c|c|c|c|c|c|}
\hline \multirow[b]{2}{*}{ Z. } & \multicolumn{3}{|c|}{ Slowly. } & \multicolumn{2}{|c|}{ Rapidly. } \\
\hline & $\begin{array}{c}\text { Time } \\
\text { befor } \\
\text { depos } \\
\tau_{0} .\end{array}$ & $\begin{array}{l}\text { aarge } \\
\text { fter } \\
\text { drop. } \\
\tau .\end{array}$ & $\begin{array}{c}\text { Edge- } \\
\text { angle. } \\
\theta .\end{array}$ & $\begin{array}{c}\text { Time of } \\
\text { discharge. } \\
\tau .\end{array}$ & $\begin{array}{c}\text { Edge- } \\
\text { angle. } \\
\theta .\end{array}$ \\
\hline $\begin{array}{l}0 \mathrm{~h} . \\
0 \mathrm{ll} . \\
8 \text { days } \\
8 \% "\end{array}$ & $\begin{array}{c}3 \\
3 \\
1.6 \\
14 \\
9.5\end{array}$ & $\begin{array}{l}21 \\
2 \\
1 \\
7 \cdot 5 \\
6 \cdot 0\end{array}$ & $\begin{array}{lr}0 & 1 \\
5 & 34 \\
7 & 36 \\
8 & 10 \\
9 & 0\end{array}$ & $\begin{array}{l}0 \cdot 82 \\
0 \cdot 1 \\
8 \cdot 5 \\
6 \cdot 5\end{array}$ & $\begin{array}{ll}8 & 20 \\
3 & 20 \\
7 & 15 \\
7 & 20 \\
8 & 11\end{array}$ \\
\hline
\end{tabular}

Whence it appears that a rapidly formed drop of water spreads upon a freshly cleansed glass plate in a thicker film than a slowly formed drop of water. The difference is imperceptible in old surfaces of glass cleansed some time previously.

The edge-angle appears to be less for rapidly-formed than for slowly-formed drops.

In the case of aqueous solutions of calcium chloride $(\sigma=1 \cdot 1639)$, potassium carbonate $(\sigma=1 \cdot 4444)$, and concentrated sulphuric acid, I have not been able to prove with certainty this difference of time of discharge between rapidly and slowly formed drops. In the case of the solutions of potassium carbonate and concentrated sulphuric acid, $\boldsymbol{\tau}_{0}$ was found greater than $\tau$; hence the time of discharge of the 
electroscope was increased by the deposited drop of liquid. This would indicate that a thin film of liquid already previously existing upon the glass (probably moisture from the atmosphere) was driven away by the deposited drop of solution and repelled from the surface of the glass.

15. Breath-figures. - Finally a series of long-known phenomena, which I have included in a treatise * "On the Condensation of Gases and Vapours on the Surface of Solid Bodies," find their natural explanation in the influence which imperceptibly thin films of liquid on the surface of a solid body exercise upon the spread and edge-angle of a liquid.

The edge-angle which lenticular drops of water, alcohol, or other liquids make with the surface of a liquid or solid body differs in magnitude with the substance, and the thickness of the imperceptibly thin film with which the surface is covered. I established this formerly $\dagger$ for mercury and other liquids, and have now proved it for solid substances such as glass, mica, silver, \&c., in the earlier part of this communication $(\$ \S 4-7)$.

Suppose the thickness of this film of substance 2 upon the solid body 1 to increase from 0 to a maximum value $D$, then the value of the edge-angle will vary continuously from the value $\theta_{1}$, corresponding to the clean surface of the substance 1 , up to the value $\theta_{2}$, corresponding to the clean surface of the liquid 2, and will then remain constant for any further increase of the thickness.

This maximum value $\mathrm{D}$ of the thickness, from which onwards the edge-angle acquires the constant magnitude $\theta_{2}$, must in general depend upon the radius of the sphere of sensible action of the molecular forces. If no change of density occur in the interior of the substance 2 (as was amply set forth above in $\$ 12)$, then of necessity $\mathrm{D}=l$.

This last is the case if the substance 2 consist not of liquid, but of some solid body whose particles admit only of a slowly occurring shifting, so that the density may be regarded as constant during the period of the experiment. This relation has indeed been employed by me $\neq$ for a determination of the magnitude $l$; and at the same time it was proved that with an increasing thickness of the solid substance 2 the edge-angle did in fact approach a constant value $\theta_{2}$. By this means, the edge-angles formed by mercury against films of iodide

* Pogg. Ann. cviii. p. 339 (1859), "Ueber Verdichtung von Gasen und Dämpfen an der Oberfläche fester Körper."

+ Pogg. Ann. exxxix. p. 64 (1870); and Phil. Mag. June 1871.

$\ddagger$ Pogg. Ann. exxxvii. p. 402 (1869). 
of silver of various thickness upon glass were, amongst others, measured.

The substance 2 of the thin film upon the surface of the solid body 1 may therefore consist, as experience teaches, either of solid or liquid.

That it may also consist of gaseous matter or condensed gas cannot be doubted, since I have completely established the influence of electrolytically separated films of gas on the bounding surface of mercury and water, or of various acids and saline solutions*.

Consequently, the surface 1 may belong to a solid body or to a liquid, and the thin film may consist of solid, liquid, or gaseous matter.

If the vapour of a liquid 3 be allowed to deposit upon the cooler surface 1 of a body rendered impure by a thin film 2, the condensed drops possess an edge-angle varying according to the thickness of the film 2 ; the places where the edgeangles have different values reflect the light in different ways ; and thus the various thicknesses of the film 2 can be estimated indirectly.

When aqueous vapour settles upon a plate of glass or metal, we obtain a so-called breath-figure, such as have been investigated principally by Moser $\dagger$ and Waidele $\ddagger$. If mercury be deposited upon a film of iodide or bromide of silver modified by light or exposure in a camera, we bave a so-called photographic image ("light-figure") or Daguerreotype, a breathfigure produced by vapour of mercury.

In order that the breath-figures may appear plainly, the thickness of the film 2 must be less than the maximum thickness $\mathrm{D}$ mentioned above.

For the production of the breath-figures it is therefore advantageous to employ the cleanest surface possible of the body 1. Surfaces of solids must therefore be freed as much as possible from the adhering film of substance 2 by polishing with alcohol, tripoli-powder, \&c.

Waidele found that freshly polished surfaces of silver gave the breath-figures best when they condensed the moisture with a blue tint, and worse when with a brown tint. This blue or brown tint I observed on the thin film of water which spreads near a drop of water upon a freshly cleansed surface of glass or silver. In the former case a portion of the drop of water spreads in a thicker film upon the solid surface before the liquid on the outer edge of the film has disappeared by

* Pogg. Ann. cliii. p. 193 (1874).

† Ibid. lvi. p. 177 ; lvii. p. 1 (1842).

$\ddagger$ Ibid. lix. p. 255 (1843). 
evaporation than in the latter case. In the former case the film exhibits a tint of higher order on Newton's scale than in the latter-blue of the 1st order corresponding to a thickness of air of about 0.0002 millim., brown of the 1st order corresponding to a thickness of about 0.0001 millim., on the supposition that the thinnest place of the film in reflected light must appear white).

A drop of alcohol deposited upon a plate, and which more readily spreads (compare $\S 6$ above) into a thicker film, even with a less-pure surface exhibits, like water, by reflected light, the blue of the 1st order.

The greater or lesser purity, and the greater or lesser capacity of the solid surface to give breath-figures, may therefore be estimated by the greater or lesser readiness with which water spreads, or by the greater or lesser thickness of the film of water which forms on breathing.

To judge by the measurements communicated in $\$ \S 4-8$, in spite of all precautions we shall never attain to the point of giving a clean surface even for a short time only to a solid body, or of keeping such for a longer time.

And safe as it may be to affirm that upon the surface of a solid body 1 a thin film of foreign matter exists, or, as I will term it, adheres, it must be difficult to determine accurately the nature and chemical properties of this adherent film. At all events by the contact or close proximity of other solids or liquids (porous substances, polished stones, coins) the thickness of the adhering film may be diminished; or it may be increased by the deposition of fresh matter. The places of different thickness are distinguished after breathing upon the surface by differing edge-angles, or different appearance in the breath-figure.

If a sheet of paper cut into a pattern be laid upon a moderately clean surface of glass, and the pattern so cut away be then breathed upon, and the moisture be again allowed to evaporate, the water vapour carries off with it a portion of the adhering film of liquid or gaseous matter, the thickness of the film becomes less, and, on repeating the breathing after the removal of the sheet of paper, the edge-angle on the parts lying undemeath the cut-away pattern will be less. The pattern will be visible in the breath-figure.

Electric currents are, as I have shown in another place*, specially endowed with the property of setting in motion liquids at the surface of solid bodies, even such as were not previously movable. The moving force is, cateris paribus, the greater as the tension of the current is greater. It cannot,

* Pogg. Ann. cxiii. pp. 514 \& 592 (1861). 
therefore, be surprising that the electric discharges meeting a surface of glass in greater or less intensity from the elevated or depressed parts of a coin, remove the adherent liquid or gaseons film more or less strongly. Add to this the heating action of the discharges passing across the film of air between the coin and the glass. The elevated and depressed parts must when again breathed on be distinguished in the breathfigure as places of greater or lesser edge-angle.

Still more readily do the electric breath-figures investigated by G. Karsten * and Riess $\dagger$ succeed, formed upon the cleanest possible surface of a recently melted plate of pitch.

These electrical breath-figures can be exhibited with vapour of mercury or of iodine $f$, instead of the moisture of the breath, since these must likewise form small lenticular drops of varying edge-angle.

If an electric spark has been discharged upon the surface of a plate of glass, mica, or metal, the adherent film will have been as good as completely remored from the places touched by the discharge. Then the water condensed on breathing will form lenticular drops no more, but will spread in a continuous film : the place hit by the spark appears glossy upon a dull ground and forms the electric breath-fgure described by Riess.

I think the results of the foregoing investigations may be summed up as follows:-

1. The long-known properties of the bounding surface common to two fluids may be extended to the bounding surface common to a fluid and a solid body.

2. The common bounding surface of a solid body 1 , and of a liquid 2 , tends to become a minimum, or, as we may say, it is governed by a surface-tension $\alpha_{12}$ independent of the geometrical form of the surface, and dependent only upon the nature of the two substances 1 and 2 .

3. The magnitude of the edge-angle of a solid body 1 and a liquid 2 , which are both bounded by fluid 3 , is determined only by the nature of the three substances, and is independent of the geometrical form of the surface.

4. The principal law of the capillary theory, given by Dr. Thomas Young, concerning the constancy of the edge-angle of the free surface of a solid body and of a liquid is a special case of the law expressed in summary 3 , in which fluid 3 consists of air.

* Pogg. Ann. lvii. p. 493 (1812).

$\dagger$ Riess, Reibungselectricität, ii. p. 224 .

$\neq$ Karsten, Pogg. Ann. lvii. p. 406 (1812). 
5. The edge-angle may be determined indirectly by deductive calculation from the measurement of the form of flat drops and bubbles, or directly by reflection of light.

6 . The edge-angle of the free surface of various liquids, such as water, alcohol, etc., and aqueous or alcoholic solutions of salts, upon clean surfaces of glass, crystals, or metals appears to be $0^{\circ}$. The liquids spread upon the clean solid surfaces.

7 . If the edge-angle has, as is usual, greater values, then the solid surface has been covered with an (imperceptibly) thin film of a foreign substance, with the thickness of which the edge-angle alters.

8. The thickness of this thin film, however, cannot exceed a certain maximum value $\mathrm{D}$, which is as great as, or greater than, the radius of the sphere of sensible action of the molecular forces.

9. This thin film adherent to the surface of the solid body may consist of solid, liquid, or gaseous matter.

10. It may also itself consist of the liquid deposited, and may be demonstrated, besides by the edge-angle, by the socalled "creeping" of salts, or by electric conduction on the surface of the solid body, and in single cases also by the interference-tints of the light reflected by it.

11. The imperceptibly thin films of the same liquid possess different properties according to the duration and the nature of their origin, or according to the nature of the solid body to which they adhere.

12. Rapidly formed drops of water spread more readily upon freshly cleansed surfaces of glass than those formed slowly.

13. These imperceptibly thin films of foreign matter appear to be the cause of the deviations between theory and experience in the determination of the surface-tension at the common boundary of liquids and solid bodies.

14. When the edge-angle is $0^{\circ}$, or has impossible values, there results a spread of the liquid upon the surface of the solid body.

15. In the case of liquids which are miscible in all proportions, the liquid with the less surfacc-tension $\alpha_{12}$ drives away that with the greater surface-tension $\alpha_{12}$. This surfacetension and the driving-away which may occur, change, however, with the nature of the solid substance. This completes Brücke's theory of the surface-diffusion along a solid surface.

16. The presence of other fluids, and particularly of air, may essentially modify the spread of a liquid upon a solid surface.

17. The dependence of the edge-angle upon the thickness 
of the imperceptibly thin film on the solid surface explains the breath-figures obtained by Moser and Waidele with water vapour, the photographic images (light-figures) of Daguerre with mercury vapour, and the electric breath-figures of $G$. Karsten and Riess with vapour of water, mercury, and iodine.

Heidelberg, June 30, 1877.

IJIX. On the Influence of Temperature on the Passage of Air through Capillary Tubes. By Francis Guthrie, LL.B.*

TN using "Marsh's" apparatus for testing for arsenic, it 1 may be noticed that, when heat is applied to the exit-tube to decompose the arsenuretted hydrogen, the liquid rises in the tube which supplies the sulphuric acid, thus leading to the supposition that the passage of the gas through the exit-tube is checked by the increase of temperature, thereby producing increased pressure. This observation suggested the following experiments on the effect of heat on the passage of gases through capillary tubes.

Fig. 1.

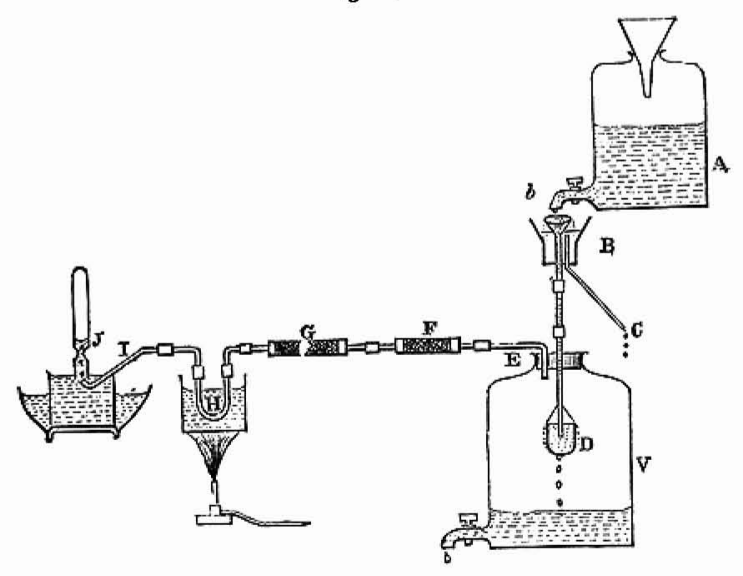

The apparatus used was as follows:-From a ressel, A, water drops into a funnel, $b$, causing a continued orerflow. The overflow falls into the concentric funnel $\mathrm{B}$, and escapes by the tube $\mathrm{C}$. The middle of the funnel-tube is removable, and may be replaced by tubes of any required lengths. The lower

* Communicated to the Physical Society, April 13, 1878. A note of the results was communicat $\in$ to the British Association, 1876 .

Phil. MLag. S. 5. Vol. 5. No. 33. June 1878. 